\title{
Determining the Carbon Dioxide Permeability Of Paint Films
}

\author{
C. Carneiro, F. Oliveira, and J. Nogueira-CIN, Corporação Industrial do Norte, S.A. *
}

A. Mendes**_Universidade do Porto ${ }^{\dagger}$

\begin{abstract}
An in-house set-up was developed for determining the permeability of paint films towards carbon dioxide. The system implemented the so-called Wicke-Kallenback method, described in EN 1062-6. This method consists of a two-chamber permeation cell divided by a supported paint film. A carbon dioxide/nitrogen mixture stream $\left(15 \% \mathrm{CO}_{2} / 85 \% \mathrm{~N}_{2}\right)$ is fed to the retentate chamber and a nitrogen carrier stream is fed to the permeate chamber. Carbon dioxide permeates from the retentate to the permeate chamber. The carbon dioxide flow rate is obtained from the permeate concentration and flow rate. From the carbon dioxide flow rate it is possible to calculate the paint film permeability towards this gas. The coating system is applied on a Kraft paper support sheet; the Kraft paper by itself shows negligible permeation resistance.

Coatings to be considered as "surface protection systems for concrete" must comply with EN 1504-2. This standard requires that the paint film permeability have an equivalent air thickness of $S_{D} \geq 50 \mathrm{~m}$. The unit developed was able to quickly determine permeabilities as low as an equivalent air thickness of $S_{D}=1500 \mathrm{~m}$.
\end{abstract}

Keywords: Carbon dioxide permeability, Wicke-Kallenback method, EN 1504-2, EN 1062-6, concrete protection, carbonation, corrosion testing, corrosion, corrosion protection

W hen reinforced concrete buildings were first constructed people believed they would last forever. We know now that this is not true and that can play a significant role in the protection of reinforced concrete. ${ }^{1}$ The EU is working on a standard for regulating coatings performance. ${ }^{2}$ Among the regulated characteristics is permeability towards carbon dioxide, which causes concrete carbonation. The carbonation process begins with the penetration of carbon dioxide (from the air) through concrete pores. Carbon dioxide reacts with calcium hydroxide present in the concrete, thus forming calcium carbonate and water. The main factors that affect the carbonation rate are: the concrete permeability and the relative humidity around the concrete (the reaction is favored when relative humidity is between 55 and $75 \%){ }^{3}$ Carbonation reduces the concrete $\mathrm{pH}$ below the passivation threshold for iron, allowing corrosion of the reinforcement. In an experimental study conducted to analyze the influence of carbonation on mechanical properties of concrete, it was concluded that the carbonated concrete could be characterized by its fragility; the changes in its mechanical properties were significant. ${ }^{4}$ The objective of the present work was to develop a simple and efficient unit to determine paint film permeability towards carbon dioxide.
The most widely used method for determining permeability is the Wicke-Kallenback (W-K) method, described in EN 1062-6. ${ }^{5}$ This method considers a permeation cell where there is no total pressure gradient between the retentate and the permeate chambers. ${ }^{6}$ The driving force is due to a partial pressure gradient, established with the help of an inert gas, usually helium or nitrogen.

The implementation of the Wicke-Kallenback method in a unit requires the use of mass flow meters, pressure transducers, and a carbon dioxide detector. The choice of the equipment should provide a reasonable compromise between high precision and low cost. In order to be operated even by nonskilled operators and to take advantage of high precision instrumentation, the unit should be fully controlled by a computer.

\section{THE WICKE-KALLENBACK PERMEATION UNIT}

A sketch of the unit developed is shown in Figure 1. The design of the permeation cell (Figure 2), is very important. It must assure a perfect mixing flow pattern in both chambers and a minimum dead volume. The carrier gas flow rate in the permeate chamber must be very low (in order to present a detectable carbon dioxide concentration at

* Estrada Nacional 13 (km 6), Apartado 1008, 4471-909 Maia, Portugal.

+ LEPAE - Departamento de Engenharia Química, Faculdade de Engenharia.

** Author to whom correspondence should be addressed. Voice: +351 22508 1695, fax: +351 22508 1449, email: mendes@fe.up.pt. 

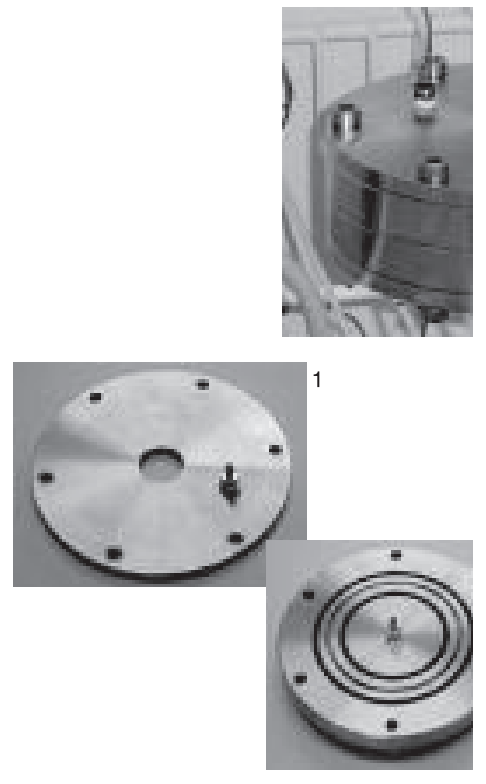

Figure 1-Sketch of the unit developed for obtaining paint films permeability towards carbon dioxide.

tion of these gases was minimized by placing the container horizontally and performing the experiment immediately after preparing the gas mixture.

The flow rate to the retentate chamber does not need to be accurately controlled, so long as it is sufficiently high enough that the concentration over the paint film is uniform and constant. However, the flow rate of the carrier gas (nitrogen) fed to the permeate chamber has to be accurately controlled. Indeed, the amount of carbon dioxide permeated is obtained from the concentration of this gas at the permeate chamber output and the input carrier flow rate. In the unit developed, the upper flow rate was controlled using a mass flow controller (range 0-100 $\mathrm{cm}^{3}{ }_{\mathrm{SPT}} /$ min and $1 \%$ FS precision, Hi-Tec Bronkhorst $^{\circledR}$, model F-201ACFAC-22-V) while the carrier flow rate was controlled using a mass flow controller (range 0-10 $\mathrm{cm}^{3}{ }_{\text {SPT }} / \mathrm{min}$ and $1 \% \mathrm{FS}$ precision, Hi-Tec Bronkhorst, model F-

the permeate outlet) and have a perfect mixing flow pattern. The design of the permeation cell is illustrated in Figure 3, which shows a photo of each of the four parts which make up the cell.

The permeation cell has a $9 \mathrm{~cm}$ internal diameter, whereas $7.8 \mathrm{~cm}$ is the effective permeation diameter. The gas distribution ring, as shown in Figure 2, is $3 \mathrm{~mm}$ deep and $2 \mathrm{~mm}$ wide and contains 45 holes with $1 \mathrm{~mm}$ diameters for gas distribution. The retentate chamber is $1 \mathrm{~mm}$ deep and the permeate chamber is $7 \mathrm{~mm}$ deep.

The gas mixture supplied to the retentate chamber was made up and stored in a $5 \mathrm{dm}^{3}$ gas container placed inside a thermostatically controlled cabinet. This mixture had a composition of $15 \%$ carbon dioxide and $85 \%$ nitrogen and was prepared using a high precision pressure sensor (range 0-0.7 MPa and 0.1\% FS precision, Druck ${ }^{\circledR}$, PMP 4010) linked to the container (Figure 1). The mixture was prepared after the container had been evacuated to a pressure lower than $500 \mathrm{~Pa}$. Carbon dioxide was the first gas to be fed to the container, followed by nitrogen, in order to promote the complete mixing of the two gases. The stratifica-
201AC-FAC-22-V). In order to ensure that there was no total pressure difference between the stream fed to both the retentate and permeate chambers, two high precision pressure transducers were used (range $0-0.2 \mathrm{MPa}$ and $0.1 \%$ FS precision, Druck, PMP 4010) (Figure 1).

The carbon dioxide analyzer ( $1 \%$ error within range, detecting different ranges, namely $0-500$ ppm and $0-10 \%$, Sable Systems ${ }^{\circledR}$, model CA-2A) was connected to a fiveway valve and analyzed the permeate, retentate, or feed streams (Figure 3). The analyzer was placed in the isothermal cabinet to improve its precision.

Data acquisition was performed using an analog-digital board (12 bits differential, Advantech ${ }^{\circledR}, 1710 \mathrm{HG}$ ) of the pressure transducers (three units) and mass flow controllers (two units). The set-points of the mass flow controllers were supplied by the same acquisition board, using the two available analog output channels. The composition was read by the analyzer and was acquired by the computer using an RS 232 interface. A software application developed in LabView ${ }^{\circledR}$ (National Instruments) was used for controlling the entire unit and for data management. The raw experimental results were calculated in an Excel $^{\circledR}$ spreadsheet.

The thermostatic cabinet was made from a high quality domestic refrigerator without freezer (Whirlpool ${ }^{\circledR}$, Class A) and a fan heater (Ufesa ${ }^{\circledR}$, TV-3602). The fan from the fan heater was connected directly to the mains and was run continuously while the heating system was connected to a temperature controller (Eurotherm ${ }^{\circledR}, 2216 \mathrm{~L}$ ) 
through a solid state relay (Eurotherm ${ }^{\circledR}$, SSR $50^{\mathrm{A}}$ ) and operated as necessary to keep the temperature constant. The temperature controller used a $\mathrm{K}$ type thermocouple to read the temperature inside the cabinet, which was stable within $0.1 \mathrm{~K}$.

\section{SAMPLE PREPARATION}

The paint film (or coating system) to be analyzed was produced by applying the paint on a Kraft paper sheet $(400 \mu \mathrm{m}$ thick) following the paint producer recommendations. In the present case, three coats were applied by roller. The paint was allowed to dry for seven days at $296.15 \mathrm{~K} \pm 1 \mathrm{~K}$ temperature and $50 \% \pm 5 \%$ of relative humidity (EN 23 270). Circular test panels of $9 \mathrm{~cm}$ diameter were then cut using a special tool and the paint film thickness was measured using a digital micrometer $\left(\right.$ Mittoyo $\left.^{\circledR}, 0-25 \mathrm{~mm}\right)$. The thickness standard deviation of eight reads was very small (Table 1). The direct thickness measurements matched with the thickness calculations based on the paint mass applied, as stated previously. It was then concluded that the penetration of these paints into the support was negligible.

\section{EXPERIMENTAL}

The W-K permeation unit was tested with two commercial paints made by CIN, a high-quality water-based paint (paint W) and a solvent-based one (paint S). The waterborne paint had $46.9 \%$ pigment volume concentration (PVC) and the solvent-based one had 32.2\%. Both paints were formulated with acrylic binders. These two high quality paints were designed for exterior applications. Generally, for resins of the same chemical nature, and in aqueous products, the carbon dioxide permeability coefficient decreased with the PVC.

The feed flow rate used was $90 \mathrm{~cm}^{3} / \mathrm{min}$, the permeate flow rate was $9 \mathrm{~cm}^{3} / \mathrm{min}$, and the cabinet temperature was 296.15 K. Determinations were performed three times.

Assuming ideal gas behavior, the permeating carbon dioxide flux, $N$, can be obtained from the following expression, ${ }^{7}$

where $y$ is the permeate carbon dioxide molar fraction, $Q$ is the permeate flow rate, $A$ is the effective permeation area, $L$ is the permeability, $\Delta p_{\mathrm{CO}_{2}}$, is the partial pressure difference between the retentate and permeate sides, and $\delta$ is the film thickness.
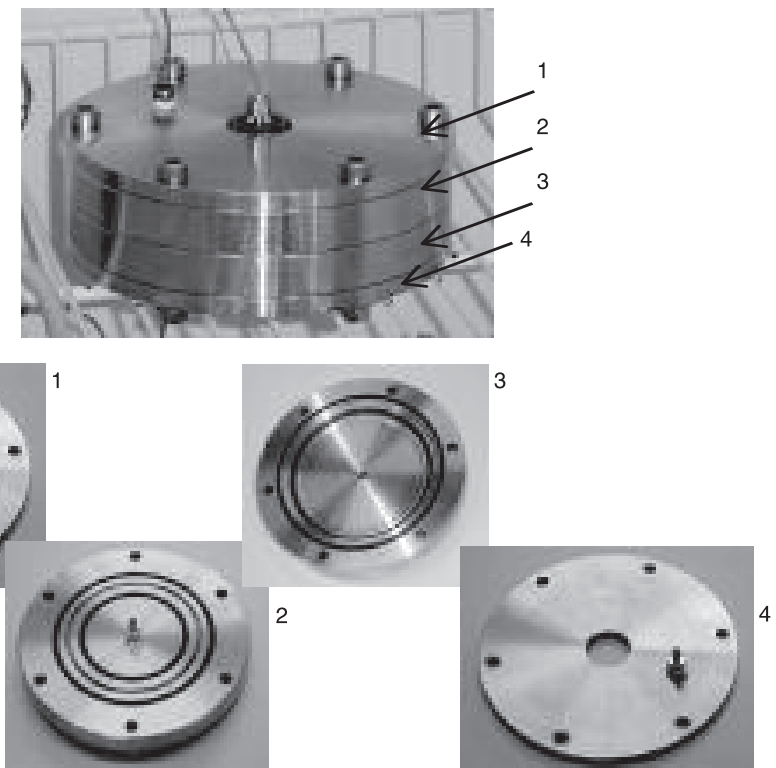

Figure 3-Wicke-Kallenback permeation cell. Part 1: inlet stream of the gas mixture. Parts 2 and 3: retentate and permeate collectors (central hole/tube) and retentate and ermeate chambers. The channel with holes is linked with parts 1 or 4 for distributing e feed and carrier. Part 4: inlet stream of nitrogen.

The partial pressure difference, $\Delta p_{\mathrm{CO}_{2}}$ (driving force), between both sides of the sample can be obtained from,

where 0.15 is the molar fraction of carbon dioxide at the retentate side and $P^{T}$ is the total pressure (which was the same on both chambers).

The paint film permeability then can be obtained from:

$$
L=\frac{N_{\mathrm{CO}_{2}}}{\frac{\Delta p_{\mathrm{CO}_{2}}}{\delta}}
$$

The paint film was not characterized alone for permeability, but together with the Kraft paper support. The support was tested alone (without any paint or coating system) and it was verified that the support permeability was very high (higher than $4 \times 10^{-12} \mathrm{~m}^{3}{ }_{\mathrm{STP}} \mathrm{m} \cdot \mathrm{m}^{-2} \mathrm{sec}^{-1} \mathrm{~Pa}^{-1}$ ) in comparison to the paint film permeability and can be neglected.

The paint film permeability is more commonly expressed as an equivalent air film thickness that shows the same mass transport resistance as the paint film. ${ }^{5}$ For obtaining such a coefficient it is necessary to calculate carbon dioxide diffusivity in air,

$$
D_{\mathrm{CO}_{2}}=1.395 \times 10^{-5}\left(\frac{T}{273.15}\right)^{1.60}
$$

Table 1-Equivalent Air Film Thickness, Diffusion Resistance Factor, and Permeability for Two Paint Films

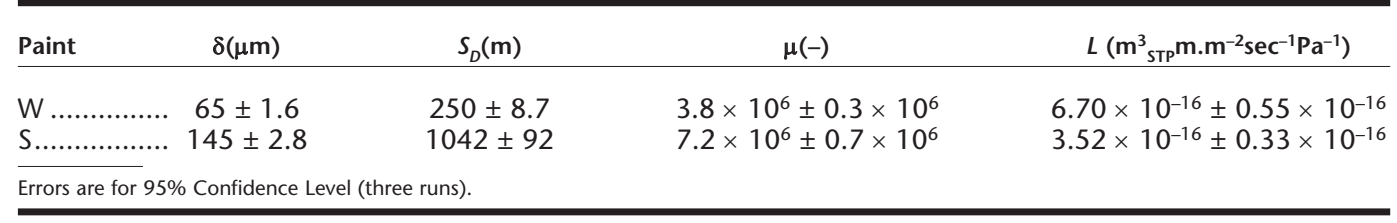




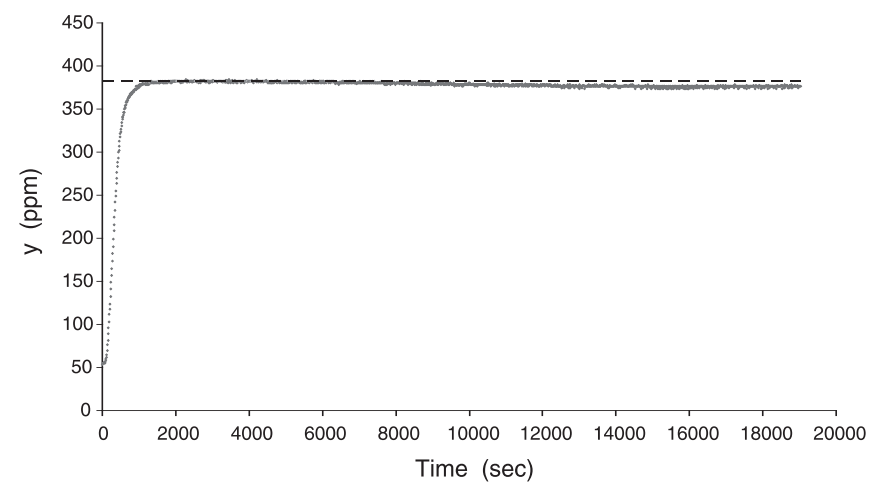

Figure 4-Permeate carbon dioxide concentration history of paint W.

where $T$ is the absolute temperature in Kelvin and the diffusivity units are $\mathrm{m}^{2} \mathrm{sec}^{-1}$. This is the Chapman-Enskog equation $^{8}$ for $101325 \mathrm{~Pa}(1 \mathrm{~atm})$ total pressure.

The equivalent air film thickness, which has the same mass transport resistance as the paint film, SD (m), is obtained from,

$$
S_{D}=\frac{D_{C O_{2}}}{D_{r} / \delta}
$$

where the effective carbon dioxide diffusivity across the paint film, $D_{r}\left(\mathrm{~m}^{2} \mathrm{sec}^{-1}\right)$, is obtained from the permeability computed before, as follows,

$$
D_{r}=\frac{L}{V_{\mathrm{CO}_{2}}} \mathfrak{R} T
$$

where $\mathfrak{R}$ is the universal gas constant and $V_{\mathrm{CO}_{2}}$ is the carbon dioxide molar volume in $\mathrm{m}^{3}{ }_{\mathrm{STP}} \mathrm{mol}^{-1}$. The ratio between the two diffusivities is known as the diffusion resistance factor, $\mu$,

$$
\mu=\frac{D_{\mathrm{CO}_{2}}}{D_{r}}
$$

and, together with the equivalent air film thickness, is used for characterizing a paint films' permeability towards carbon dioxide.

The results obtained for these paints are given in Table 1. Figure 4 shows the plot corresponding to the carbon dioxide concentration history at the permeate side for paint $\mathrm{S}$.

It can be seen from Table 1 that the results are reproducible (average error, $t$-distribution, and 95\% confidence level). Table 2 contains some polymer permeabilities towards carbon dioxide. (This data is provided for comparison with the paint films' permeabilities shown in Table 1.) Note the higher permeability of PDMS, a high permeable rubbery polymer, and the comparable permeability of PPO, a high permeable glassy polymer. Kapton and PSF polymers, both glassy, show significantly lower permeabilities.

Table 2-Single Polymer Film Permeability Towards Carbon Dioxide

$$
\text { Polymer }
$$

$L\left(m_{\text {STP }}^{3} \mathrm{~m} \cdot \mathrm{m}^{-2} \mathrm{sec}^{-1} \mathrm{~Pa}^{-1}\right)$

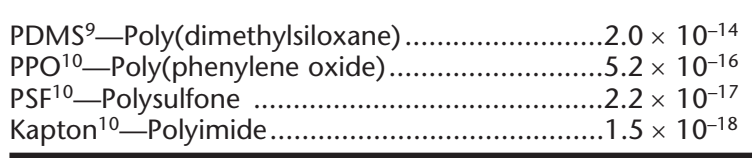

The apparatus described allows for the quick determination of paint film permeabilities. A typical complete run lasts less than eight hours, not only because the concentration values are acquired each second using a computer, but also due to the permeation cell design and the precision of the selected instruments. With this unit it was possible to follow directly the permeate concentration and to compute straightforwardly the paint film permeability down to a permeability of $10^{-18} \mathrm{~m}^{3}{ }_{\text {STP }} \mathrm{m} \cdot \mathrm{m}^{-2} \mathrm{sec}^{-1} \mathrm{~Pa}^{-1}$.

\section{CONCLUSIONS}

A Wicke-Kallenback permeation unit was successfully designed, built, and optimized for determining the permeability of paint films towards carbon dioxide, according to EN 1062-6. A sensitivity analysis showed that the precision error affecting permeability is directly dependent on the permeate chamber volume and the permeate mass flowrate instrument and concentration analyzer precision errors. The limiting precision error is the concentration analyzer error. It is, however, possible to set the operating conditions, basically the carrier flow rate, to maximize the permeability precision.

Results obtained were within $10 \%$ error, which is quite good in view of the precision of the concentration analyzer for the concentration level read, $\pm 5 \mathrm{ppm}$ precision error, which led to a permeability error of $\pm 8 \%$. The minimum permeability possible to be analyzed directly with this unit is $1 \times 10^{-18} \mathrm{~m}_{\text {STP }}^{3} \mathrm{~m} \cdot \mathrm{m}^{-2} \mathrm{sec}^{-1} \mathrm{~Pa}^{-1}$.

A patent disclosing the permeability unit described here was recently submitted to the Portuguese patent office (PT 103 373).

\section{ACKNOWLEDGMENTS}

The authors acknowledge Prof. Fernão D. Magalhães and Dr. João Santos for their essential help in the software development.

\section{References}

(1) Viness, T.L. and Manager, P.E., "Architectural Coatings for Repair and Protection of Concrete Facades," Materials and Construction: Exploring the Connection: Proceedings of the 5th ASCE Materials Engineering Congress, Cincinnati, OH, 232-239, 1999.

(2) EN 1504-2, "Products and Systems for the Protection and Repair of Concrete Structures-Definitions, Requirements, Quality Control and Evaluation of Conformity-Part 2: Surface Protection Systems for Concrete," April 2004.

(3) International Report, "Design Manual for Roads and Bridges," Volume 2, Section 4, Part 3, A/6, May 2004.

(4) Jerga, J., "Physico-Mechanical Properties of Carbonated Concrete," Construction and Building Materials, Vol. 18, 645-652, 2004.

(5) EN 1062-6, "Paints and Varnishes-Coating Materials and Coating Systems for Exterior Masonry and Concrete-Part 6: Determination of Carbon Dioxide Permeability," 2004.

(6) Ruthven, D., Principles of Adsorption and Adsorption Processes, John Wiley \& Sons, NY, 1984.

(7) Mulder, M., Basic Principles of Membrane Technology, Kluwer Academic Publishers, Dordrecht, 2nd Ed., 1996.

(8) Bird, R., Stewart, W., and Lightfoot, E., Transport Phenomena, John Wiley \& Sons, NY, 2nd Ed., 2001.

(9) Internal information at GKSS-Geesthacht, Germany, 1994.

(10) Pixton, M., Paul, D., and Yampol'skii, Y., "Relationships Between Structure and Transport Properties for Polymers with Aromatic Backbones," in Polymeric Gas Separation Membranes, Paul, D. and Yampol'skii, Y. (Eds.), CRC Press, Boca Raton, FL, 1994. 